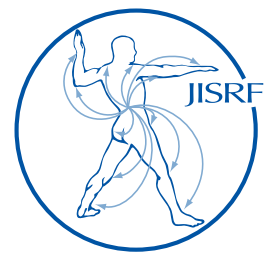

\title{
Prosthetic Fracture of a Cemented Exeter Femoral Stem
}

Facek $M^{1}$, Khatib $Y^{1}$, Swarts $E^{2}$

\begin{abstract}
We present a single case of fracture of an Exeter femoral prosthesis at the neck, occurring after a fall from standing height, in a lean $70 \mathrm{yr}$ lady at 6 years post implantation. The fracture propagated from the insertion dimple on the superior aspect of the prosthesis shoulder. Materials analysis suggested variance in composition of the alloy, particularly with grain size heterogeneity. Whilst Exeter femoral prosthesis fracture is extremely rare, when it does occur the literature suggests it is often in the context of excessive mechanical stresses (obesity, high offset, falls). However, this case may represent a failure of materials rather than mechanical stresses alone.
\end{abstract}

Keywords: hip arthroplasty, prosthesis failure, stem fracture, hip prosthesis, revision total hip replacement

Level of Evidence: AAOS Therapeutic Level IV

\section{Introduction}

The Exeter ${ }^{\mathrm{TM}}$ Universal hip stem (Stryker Inc., Newbury, UK) is a commonly used and well-performing prosthesis in hip arthroplasty. The Australian Orthopaedic Association National Joint Replacement Registry has recorded its use in 91, 601 procedures, which includes 71,849 total hip replacements and 19,752 hip hemiarthroplasties (unipolar, bipolar and trauma stem types), of both the older Exeter type and modern Exeter V40 type. [1] The overall revision rate for all stem types is low, at 0.61 revisions/100 observed years.

The Exeter stem is a highly polished, double tapered, stainless steel stem, designed for use with acrylic bone cement. The modern or Universal Exeter stem was introduced in 1988 with the addition of more sizes and offset options while preserving the original shape and design. [2]
The Exeter stem is reported to have excellent long term survival results, and failure due to stem fracture is an extremely rare occurrence. $[\underline{3}, \underline{4}]$

\footnotetext{
1 Dr Michael Facek BSc; Dr Yasser Khatib BSc(Med) MBBS, M Sports Med, FRACS (Orth), FAOrthA

Department of Orthopaedics, Nepean Hospital, Sydney, NSW, AU (Direct reprint requests to Michael Facek)

2 Dr Eric Swarts Department of Medical Engineering and Physics, Royal Perth Hospital, Perth 6000, Western AU
}

(C) 2016 Facek, Khatib, Swarts. All rights reserved. Authors retain copyright and grant the journal right of first publication with the work. Reconstructive Review follows the Creative Commons Attribution-NonCommercial CC BY-NC. This license

allows anyone to download works, build upon the material, and share them with others for non-commercial purposes as long as they credit the senior author, Reconstructive Review, and the Joint Implant Surgery \& Research Foundation (JISRF). An example credit would be: "Courtesy of (senior author's name), Reconstructive Review, JISRF, Chagrin Falls, Ohio". 


\section{Case Report}

Our patient is a healthy and lean $(71 \mathrm{~kg}) 70$ year old female, who underwent routine right hip arthroplasty in 2009 for osteoarthritis, via posterior approach. A cemented, flanged polyethylene cup (Contemporary Acetabulum, Stryker Inc.) was inserted with a cemented, size 0 Stryker Exeter V40 stem with $44 \mathrm{~mm}$ offset, and a metal $(\mathrm{CoCr})$ $28 \mathrm{~mm}+0$ head. Our patient had an unremarkable post-operative recovery and her hip arthroplasty had been functioning well with no complications.

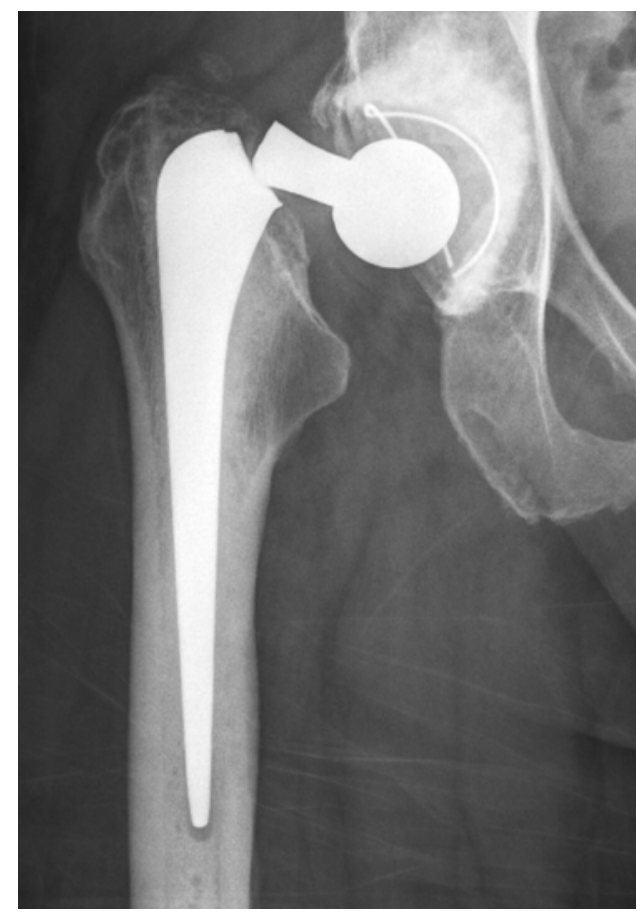

Fig 1: Prosthetic fracture of a polished, tapered, collarless femoral stem; a cemented polyethylene cup has been used.

In June 2015, she had a fall from standing height causing a painful right hip. Radiographic examination showed a femoral prosthetic fracture at the base of the neck of the femoral component (Fig 1).

After discussion and appropriate consent, we performed cement-in-cement revision surgery to exchange the broken femoral stem using a new Exeter femoral component. Intra-operatively, the implant appeared well-fixed without signs of loosening or infection. Positioning of the cup and stem and were appropriate, with an intact satisfactory cement mantle, although the shoulder of the stem was proud of the level of femoral osteotomy by $10 \mathrm{~mm}$.

The stem fracture had initiated from the insertion guide 'dimple', at the point of its maximum diameter, and propagated transversely (Fig 2). The proximal neck fragment and taper well were engaged with the femoral head, and in turn were located in the acetabular component. The acetabular component had an intact rim with no signs of neck impingement and no evidence of eccentric wear of the cup.

The patient underwent revision of the femoral stem uti-

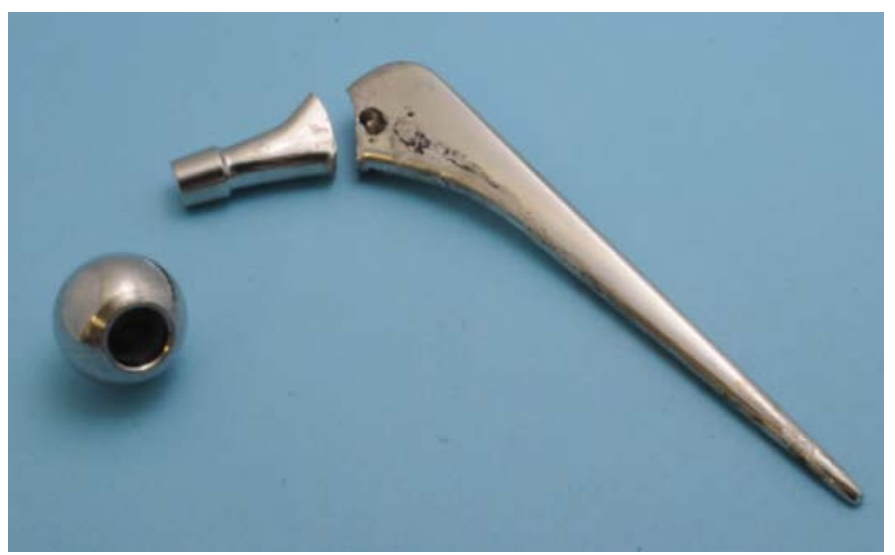

Fig 2: The prosthetic stem fracture propagated inferiorly from its origin at the insertion "dimple".

lizing the previous posterior approach and a cement-in-cement revision technique. The stem was removed without damaging the cement mantle, and a smaller stem of the same design (Exeter $44 \mathrm{~mm}$ No.00) designed for the use in cement-in-cement revisions was used. The cement cavity was cleaned and thoroughly dried, and the new stem installed using cement within the existing mantle with a hollow centraliser (Fig 3). The surgical procedure proceeded successfully and the patient made an uneventful recovery. She was allowed to mobilise full weight bearing on day one and received rehabilitation with physiotherapy prior to discharge 6 days after surgery. Our patient received routine post-operative follow up and reported good function with Oxford Hip Score 37, 12-months after her revision surgery.

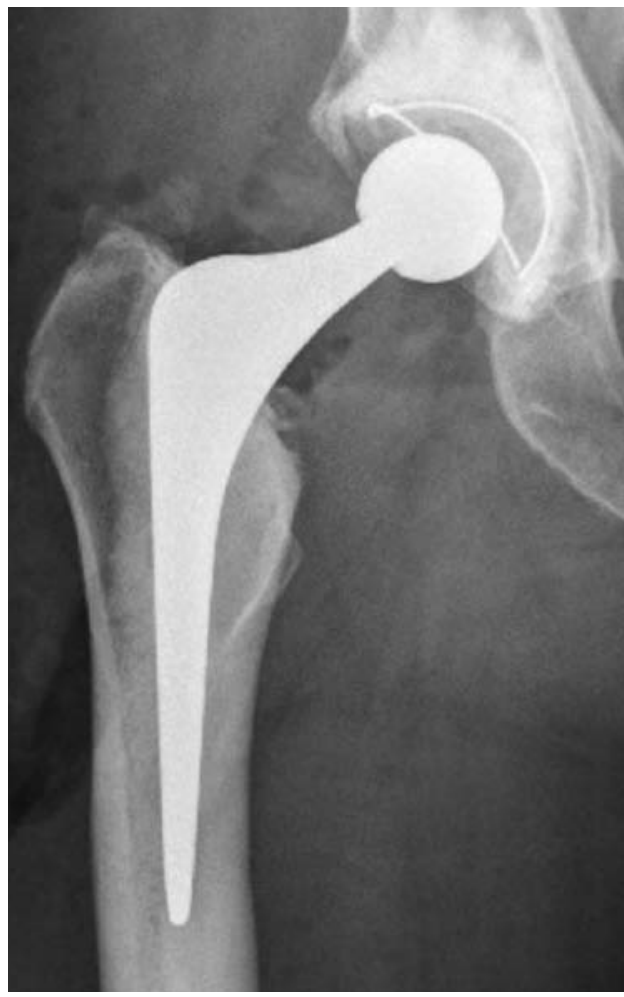

Fig 3: Successful cement-in-cement technique using smaller sized stem. 


\section{Results}

Retrieval analysis of the fractured Exeter components was performed. Macroscopically, "beach marks" were seen across the fractured surface, a sign of chronic material fatigue (Fig 4). Evidence of corrosion was detected

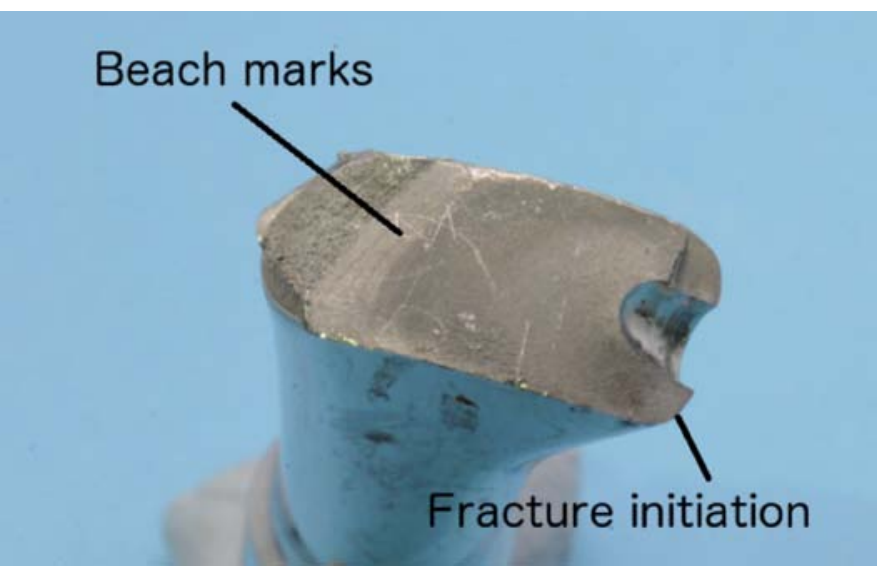

Fig 4: Concentric "beach marks" seen at the fracture plane, an indication of material fatigue; they represent successive arrests or decreases in the rate of fatigue crack growth due changes in material loading over time. This pattern indicates rapid progression from the initiation site, and slower progression where the beach marks are seen.

along the medial edge and posterior surface of the stem, with minor corrosion in the trunion and no evidence of corrosion on the neck. The stem exhibited heterogeneity of microstructure; specifically, there was a high proportion of large grains near the prosthesis surface, which can be observed when an alloy has re-crystallized after heat-treatment, whereas the rest of the stem was fine-grain austenite (Fig. 5). This variance in composition has been noted in previous prosthesis retrieval analysis []ㅡ which showed that coarse grain size, and grain heterogeneity, were consistent with lower fatigue and yield strengths.

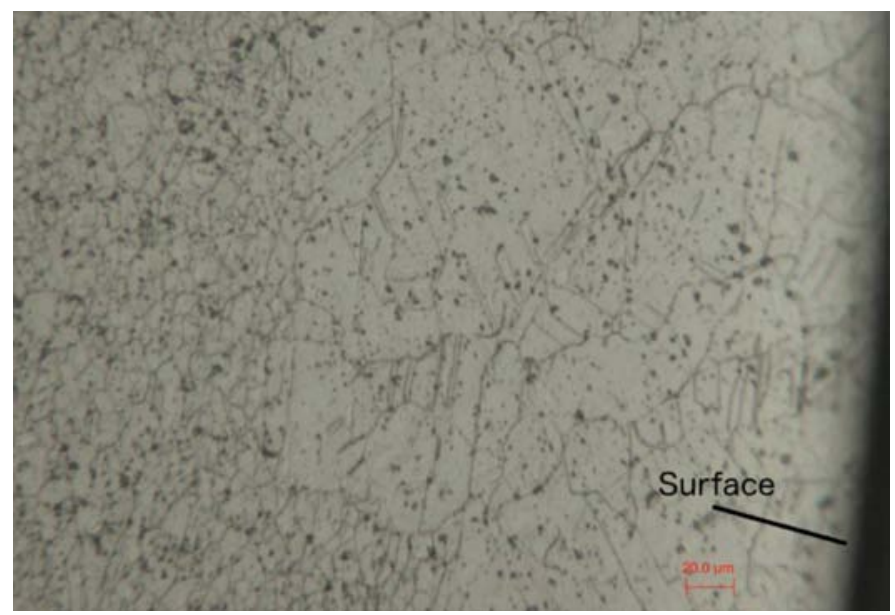

Fig 5: Variability in grain microstructure between surface region (right side) and central portion (left side) of prosthesis seen on this high power view.
Chemical analysis of the stem composition was undertaken with SpectroMaxx Optical Emission Spectroscopy (OES) to verify composition; there were minor, non-significant aberrations in manganese and nitrogen, but no evidence of abnormalities to account for fracture (Table 1). More significant was variability of microhardness with distinct hardness difference according to grain size. The average hardness of large grains was $292 \mathrm{Hv}$, while average hardness of small grains was $362 \mathrm{Hv}$.

Table 1: Chemical analysis

\begin{tabular}{|l|c|c|}
\hline Element & Composition \% & Composition limits (ISO 5832-9) \\
\hline Carbon & 0.05 & $0.08 \max$ \\
\hline Silicon & 0.25 & $0.75 \max$ \\
\hline Manganese & 4.32 & $2-4.25$ \\
\hline Nickel & 9.3 & $9-11$ \\
\hline Chromium & 21.7 & $19.5-22$ \\
\hline Molybdenum & 2.2 & $2-3$ \\
\hline Niobium & 0.28 & $.25-0.8$ \\
\hline Sulphur & 0.003 & 0.01 \\
\hline Phosphorus & 0.02 & 0.025 max \\
\hline Copper & 0.07 & 0.25 max \\
\hline Nitrogen & 0.56 & $0.25-0.5$ \\
\hline Iron & balance & balance \\
\hline
\end{tabular}

Chemical composition of the femoral stem compared to composition limits outlined in ISO 5832-9, showing only manganese and nitrogen to be slightly outside specified norms.

SEM of the fracture surface revealed dimple rupture, cracking, beach marks and some areas showing fatigue striations, common to a fatigue failure. Apart from the insertion guide hole, no other obvious stress risers were detected near the crack initiation zone. The fracture initiated at the anterosuperior edge of the stem in close proximity to the stem insertion guide hole. Lack of proximal bone or cement support at this region can result in increased bending forces.

\section{Discussion}

The Exeter ${ }^{\mathrm{TM}}$ stem is a polished and double-tapered collarless stainless steel stem with a "V40" Morse taper and a hollow distal centraliser which allows subsidence for compressive loading throughout the cement mantle. There is a "dimple" on the superior aspect of the shoulder to allow the introducer pin to secure the stem during insertion, a potential stress riser which was relevant in this case.

The evolution of the Exeter stem is relevant as much of the previous literature reviewed older stem generations 
that are no longer used. The polished, double-tapered collarless Exeter stem originated in 1970, manufactured from stainless steel alloy (EN58J); at the time, British manufacturing standards required that stems made of this alloy be polished. It was designed for a posterior approach, and the rationale for the double taper was to improve cement compression during insertion. The stem had good results, but due to reports of fracture at the neck, the material was changed to 316L stainless steel in 1976; at the same time, the surface finish was altered to a matte type. In 1983, nitrogen was added to create an alloy that was stronger and more corrosion resistant; this was classed as a "high-nitrogen stainless steel" (HNSS) and marketed as Orthinox ${ }^{\mathrm{TM}}$. The finish was ultimately reverted to the polished type in 1986 due to inferior results.

The Exeter is a superior prosthesis with a long history and excellent long term results in all major registries [ $\underline{6}]$. Specifically, the Contemporary/Exeter stem combination has a $10 \mathrm{yr}$ revision rate of ranging from 3.2-6.0\% depending on acetabular component choice. [1] Prosthesis fracture rates are extremely low in modern type HNSS stems with polished, tapered morphology.

Beach marks and fatigue striations noted on the fracture surface in our case indicate a fatigue mode of failure. Variation in microstructure, as well as hardness, suggest alloy segregation. Large grains near the surface are most likely a form of secondary recrystallization as a result of heat treatment. These are significant factors that can predispose the stem to failure. Unfortunately this is not an isolated case and we have observed grain size and hardness variation on five previous Exeter stem fractures. [] Only the manganese and nitrogen concentration slightly exceeded the compositional limits outlined in ISO 5832-9. These are only minor non-conformances and would not be expected to have any influence in stem failure. Other clinical factors that may have contributed to failure include: patient fall, medium to high activity level and femoral canal morphology.

There are very few reports in the literature of femoral prosthetic fractures at the neck or trunion, and most of these date back to use of out-dated designs and materials. In 1995, Rokkum reported on a series of 3 stem fractures in a cohort of 27 Exeter hips that were followed over 10 years [2] but this was an analysis of older style stems manufactured between 1983 and 1985. More recently, Yates et al reported on two prosthetic neck fractures, both in obese patients (BMI 33 and 49) who were very active, and with high-offset (44mm) stems [7]. They made particular note of the variability in grain size seen with one of those two stems after metallurgical analysis, and hypothesized that the combination of high loads and material aberrations may contribute to neck fracture.

Swarts et al (2007) examined 6 fractured femoral stems, which occurred within a 3 year period (2002-5), four of which were Exeter stems; all were of modern design with HNSS components [ㅍ]. The fractured stems were all examined by stereomicroscopy and scanning electron microscopy, and their chemical composition determined. Three of the fractures occurred at stem and only one occurred at the superior aspect of neck, although it was not at the insertion guide hole as in our case. None had chemical composition anomalies. Swarts hypothesized that an abundance of coarse grains near the surface in the stems that fractured (an abnormality in the manufacture process) was detrimental to controlling micro-fracture propagation and hence shortened the fatigue life; they suggested further microstructural optimization as part of the manufacture process.

Yates (2008) reported on 5 Exeter prosthesis fractures, two of which were fractures of the neck [7]. They proposed a distinction in the cause of fractures of the prosthetic neck (which they associated with mechanical overload) and stem fractures (associated with fatigue fracture and grain size anomalies). The neck fractures were again not associated with the insertion guide hole. Akinola (2009) then reported on a single case of Exeter prosthetic neck fracture in a $121 \mathrm{~kg}$ male who had a fall from standing height [] $]$. In agreement with the suggestion of Yates, the failure was attributed to mechanical overload, and the authors suggested a recommended maximum weight be considered for the Exeter prosthesis. O'Neil (2011) et al reported on a single Exeter prosthetic neck fracture that had propagated from the insertion guide hole, just as in our case [9]. This stem however was a cement-in-cement type, which is narrower in design. The failure occurred at 5 years post implantation in a patient with a BMI of 27.8.

Davies (2013) reported on four fractures of modern design V40TM Exeter stems, all of which occurred within the body [10]. All four of the patients were classed as obese. Three of the patients were noted to have "low" neck cuts, with proud shoulders, although the authors noted that the technique guide specifically refers to the neck resection as unimportant.

Hamlin et al (2014) reported on a single case of Exeter prosthesis fracture at the trunion-neck junction, in an obese $(141 \mathrm{~kg})$, elderly male patient who sustained a fall from standing height [11]. He was also noted to have a relatively under-sized stem. Analysis of the stem concluded the fracture had initiated from the lateral side of the trunion-neck junction, and was due to fatigue. They proposed that consideration be given to the situation of highly overweight patients given the increased stresses they subject a standard prosthesis to, and highlighted that the problem 
may become increasingly frequent given the trend in rising BMI globally.

Reito et al (2015) reported on three fractured Exeter prostheses, all of which occurred more proximally along the neck, and near to the trunnion [12]. All patients were overweight (BMI>25, weights of $84 \mathrm{~kg}, 92 \mathrm{~kg}$ and $120 \mathrm{~kg}$ ), with higher offset stems (No. 44), 36mm heads and "plussize" heads $(+5 \mathrm{~mm},+8 \mathrm{~mm}$ and $+10 \mathrm{~mm}$ offsets). They reviewed their series of 2,521 Exeter femoral stems to calculate a prosthesis fracture rate of $0.1 \%$ overall. They hypothesized that the combination of obese patients, high offset stems and large heads (with extended offsets) may be increasing lever arm forces significantly, and may warrant investigation.

In our case we believe the factors implicated in the Exeter stem fracture include:

- Poor proximal support (loosening)

- Canal morphology (champagne-glass femurs)

- Poor microstructural homogeneity

- Surface corrosion

\section{Conclusion}

The Exeter femoral stem has a long history with reliable results. There are few reports in the literature of failure at the prosthetic neck, and these rare cases are associated with increased mechanical strain: falls, increased body weight, increased offset, and increased femoral head size. The failure of the Exeter prosthesis in our case is likely a result of a combination of factors including poor microstructural homogeneity, high patient activity level, poor proximal support and a mechanical fall. Our case is unique in that the patient had few of the typical risk factors; whilst she did have a No. 44 stem, she was not overweight, and had a smaller prosthetic head $(28 \mathrm{~mm})$ without increased offset. Her materials analysis may indicate that some degree of manufacture variance may have contributed to her prosthesis fracture. Future cases of prosthetic neck failure should undergo material analysis.

\section{Disclosure}

The authors declare that there are no conflict of interest regarding the publication of this paper. For full disclosures refer to last page of this journal.

\section{References}

1. Australian Orthopaedic Association National Joint Replacement Registry. Annual Report. Adelaide:AOA; 2015.

2. Rokkum M, Bye K, Hetland KR, Reigstad A. Stem fracture with the Exeter prosthesis. 3 of 27 hips followed for 10 years. Acta orthopaedica Scandinavica. 1995 Oct;66(5):435-9. PubMed PMID: 7484124.

3. Ling RS, Charity J, Lee AJ, Whitehouse SL, Timperley AJ, Gie GA. The longterm results of the original Exeter polished cemented femoral component: a follow-up report. The Journal of arthroplasty. 2009 Jun;24(4):511-7. PubMed PMID: 19282139.

4. Williams HD, Browne G, Gie GA, Ling RS, Timperley AJ, Wendover NA. The Exeter universal cemented femoral component at 8 to 12 years. A study of the first 325 hips. The Journal of bone and joint surgery British volume. 2002 Apr;84(3):324-34. PubMed PMID: 12002487.

5. Swarts E, Kop A, Jones N, Keogh C, Miller S, Yates P. Microstructural features in fractured high nitrogen stainless steel hip prostheses: A retrieval study of polished, tapered femoral stems. Journal of Biomedical Materials Research Part A. 2008;84A(3):753-60.

6. Hamlin K, MacEachern CF. Fracture of an Exeter stem: A case report. JBJS Case Connect. 2014;4(3):e66.

7. Yates PJ, Quraishi NA, Kop A, Howie DW, Marx C, Swarts E. Fractures of modern high nitrogen stainless steel cemented stems: cause, mechanism, and avoidance in 14 cases. The Journal of arthroplasty. 2008 Feb;23(2):188-96. PubMed PMID: 18280411.

8. Akinola B MT, DeRoeck N. Fracture of an Exeter stem-a case report. The Internet Journal of Orthopedic Surgery. 2009;16(1).

9. O'Neill GK, Maheshwari R, Willis C, Meek D, Patil S. Fracture of an Exeter 'cement in cement' revision stem: a case report. Hip international : the journal of clinical and experimental research on hip pathology and therapy. 2011 SepOct;21(5):627-9. PubMed PMID: 21948033

10. Davies BM, Branford White HA, Temple A. A series of four fractured Exeter stems in hip arthroplasty. Annals of the Royal College of Surgeons of England. 2013 Nov;95(8):e130-2. PubMed PMID: 24165328. Pubmed Central PMCID: 4311545.

11. Hamlin K, MacEachern CF. Fracture of an Exeter Stem. A Case Report. 2014 2014-08-13 00:00:00;4(3):e66.

12. Reito A, Eskelinen A, Pajamaki J, Puolakka T. Neck fracture of the Exeter stem in 3 patients. Acta orthopaedica. 2016 Apr;87(2):193-6. PubMed PMID: 26541359. 